\title{
THE RELATIONSHIP OF THE EFFECT OF INTRA-ARTICULAR PLATELET-RICH PLASMA (PRP) ADMINISTRATION WITH THE SEVERITY OF KNEE OSTEOARTHRITIS
}

\author{
Eklem İçi Uygulanan Trombositten Zengin Plazmanın (TZP) Etkisinin Diz Osteoartritinin \\ Şiddeti ile İlişkisi
}

\author{
Birhan OKTAȘ ${ }^{1}$ İbrahim Deniz CANBEYLİ ${ }^{2}$ \\ ${ }^{1,2}$ Kırıkkale Üniversitesi Tıp Fakültesi Ortopedi ve Travmatoloji AD Yahşihan, KIRIKKALE, TÜRKIYYE
}

Amaç: Trombositten zengin plazma uygulamaları son dönemde diz osteoartritinde cerrahi dışı tedaviler arasında yer almaya başlamıştır. Plasebo ve proloterapi gibi tedavilere üstünlüğü gösterilmiştir. Ancak halen erken dönem ve geç dönem diz osteoartriti üzerine etkisinin değişiklik gösterip göstermediği tam net değildir. Biz bu çalışmamızda farklı evredeki diz osteoartriti olan hastalarda tek doz trombositten zengin plazma uygulamasının etkinliğini karşılaştırmayı amaçladık.

Gereç ve Yöntemler: Tek dizine tek doz trombositten zengin plazma uygulanmış ve enjeksiyon öncesi Lysholm diz fonksiyonelliği skoru anketi doldurulmuş olan toplam 80 hasta çalışmaya dahil edildi. Bu hastaların daha önce çekilmiş grafileri üzerinden Kallgren-Lawrence osteoartrit sinıflaması kullanılarak sinıflama yapıldı. Evre I ve II osteoartriti olanlar 1. gruba dahil edilirken, evre III ve IV osteoartriti olanlar 2. gruba dahil edildi. $\mathrm{Bu}$ hastaların enjeksiyon öncesi ve sonrasında doldurulmuş olan Lysholm diz fonksiyonelliği anketleri değerlendirildi. Elde edilen veriler her iki grup arasında varyans analizi kullanılarak (ANOVA) karşılaştırıldı.

Bulgular: Her iki grubun Lysholm skorlarında enjeksiyon sonrası iyileşme mevcuttu. Her iki grupta da hem ağrı hem fonksiyonellik açısından daha iyi sonuçlar elde edildi. Enjeksiyon öncesi ve sonrası skorlardaki değişim ele alındığında, birinci gruptaki değişim ikinci gruba göre anlamlı olarak daha fazlaydı. $(\mathrm{p}<0,05)$

Sonuç: Trombositten zengin plazma uygulaması erken evre diz osteoartritli hastalarda daha etkili idi. Tek doz uygulama hem ağrının azaltılmasında hem de fonksiyonelliğin artırılmasında yeterli bulunmuştur. Ancak ileri evre osteoartritli hastalarda en az 3 doz yapılması, cevap alınamadığında bir sonraki tedavi yöntemlerinin düşünülmesi gereklidir.

Anahtar Kelimeler: Osteoartrit, diz, trombositten zengin plazma, Lysholm diz skoru
Objective: Platelet-rich plasma applications have recently become one of the non-surgical treatments in knee osteoarthritis. It has been shown to be superior to treatments such as placebo and prolotherapy. However, it is not entirely clear whether its effect on early or late knee osteoarthritis varies. In this study, we aimed to compare the effectiveness of single dose platelet-rich plasma administration in patients with different stages of knee osteoarthritis.

Material and Methods: A total of 80 patients who received a single dose of platelet-rich plasma to a single knee joint and whose Lysholm knee functionality score questionnaires were filled before injection were included in the study. Knee radiographies of all patients were evaluated according to Kellgren-Lawrence classification. Stage I and II osteoarthritic patients were included in Group 1 whereas Stage III and IV osteoarthritic patients were included in Group 2. Knee scores of all patients acquired before and after injection therapies were evaluated. Demographic data were also evaluated. All data obtained were compared between two groups using statistical analysis ANOVA.

Results: Scores of both groups were increased as compared to pre-injection scores. Better results were obtained in both groups in terms of pain and functionality. When the changes in scores before and after injection of both groups were compared, the first group had a better result statistically $(\mathrm{p}<0,05)$.

Conclusion: Platelet-rich plasma application was more effective in early stage osteoarthritic patients. Single dose administration has been found to be effective in pain control and functionality. However, in case of late stage osteoarthritis, a minimum dose of 3 injections should be administered or other treatment modalities can be tried.

Keywords: Osteoarthritis, knee, platelet-rich plasma, Lysholm knee score

\section{GíRIŞ}


Diz osteoartriti, toplumun artan kilosu ve değişen yaşam koşulları nedeniyle sıklığı artan bir toplum sağlığ1 sorununa dönüşmüştür. Özellikle kadın cinsiyeti daha sık tutar ve ileri yaşlarda ambulasyonu kötü yönde etkiler (1). Tedavisinde ilk basamak olarak fiziksel tıp modaliteleri, ilaç tedavisi, eklem içi enjeksiyonlar yer alır iken, nihai tedavisi cerrahidir (2). Cerrahi tedaviler oldukça invaziv olmaları, maliyetlerinin yüksek olması ve ek komplikasyonları nedeniyle son çare tedaviler olarak karşımıza çıkmaktadırlar (1). Son dönemde daha çok konservatif ve invaziv olmayan tedavilere eğilim artmaktadır. $\mathrm{Bu}$ tedavilerin başında eklem içi enjeksiyonlar gelmektedir. Bunlar arasında visko-suplementasyon, steroidler ve zenginleştirilmiş rejeneratif tıp ürünleri yer alır. Rejeneratif tıp ürünleri arasında yer alan kan ürünlerinden TZP (Trombositten-zengin Plazma) ve kök hücre uygulamaları son yıllarda popülerlik kazanmıştır (3). İçerdiği büyüme faktörleri ve adezyon molekülleri nedeni ile kıkırdak, kemik, tendon ve kas dokusunda yenileyici ve tamir edici özellikleri olması nedeniyle kullanımı artmıştır (4). Ancak bilinmektedir ki, hazırlanan süspansiyonun içeriği ve özellikleri de etkisi üzerinde rol oynamaktadır (5). Osteoartritte de kıkırdak yenilenme kapasitesini artırdığ 1 son çalışmalarda gösterilmiştir (3). Birçok merkezde osteoartrit nedeniyle eklem içi TZP uygulamaları yapılmaktadir. $\mathrm{Bu}$ uygulamalarda hastalar farklı derecede fayda görmekte, kimisi hiçbir fayda görmemektedir. Hazırlanan enjeksiyonun kalitesi kadar etkilenen eklemin osteoartrit derecesinin de bunda etkili olduğunu düşünmekteyiz. Şu ana dek literatürde, osteoartrit şiddeti ile TZP enjeksiyonu sonrası görülen faydanın karşılaştırıldığı bir çalışma yoktur. Biz bu çalışmamızda erken evre osteoartritli hastaların daha fazla fayda görebileceğini, ileri evre osteoartritli hastaların ise kısmen ya da belirsiz fayda göreceğini göstermeyi ve gereksiz maliyetli tedavilerin önlenmesini amaçladık.

\section{GEREÇ VE YÖNTEM}

Yerel etik kuruldan (Kırıkkale Üniversitesi Girişimsel Olmayan Çalışmalar Etik Kurul Başkanlığl; 18.12.2019-2019.11.08) gerekli izinler alınarak çalışmamız tasarlandı. Polikliniğimize 01.01.201831.12.2019 tarihleri arasında diz osteoartriti ile başvuran ve eklem içine TZP enjeksiyonu yapılmış olan hastalar geriye dönük olarak tarandı. Tek taraflı ya da bilateral TZP yapılmış olan 100 hasta verisine ulaşıldı. Bu hastalara TZP tedavisi sonrası izometrik ev egzersiz programı verilmişti. $\mathrm{Bu}$ hastalardan enjeksiyon öncesi Lysholm diz fonksiyonelliğini belirten anket doldurulmuş olan 80 tanesi çalışmaya dahil edildi. $\mathrm{Bu}$ hastalardan tek enjeksiyon sonrası 3 ay ve daha fazla süre geçenlerine e-posta ya da telefon yoluyla ulaşılarak sözel Lysholm anketi dolduruldu. Lysholm anketinin Türkçe geçerlilik ve güvenilirlik çalışması yapılmıştır (6). Son enjeksiyonun üzerinden 3 aydan daha kısa ya da 1 yıldan daha fazla süre geçmiş olan hastalar çalışmaya dahil edilmedi. Ayrıca herhangi bir nedenle diz operasyonu geçirmiş olan ve eklemleri tutabilecek sistemik hastalık tanısı alan hastalar da çalışmadan çıkarıldı. Elde edilen hastaların enjeksiyondan önce çekilmiş diz grafileri değerlendirilerek şüpheli ve hafif derece diz osteoartriti bulunanlar Grup 1, orta ve ileri evre diz osteoartriti bulunan hastalar Grup 2 olarak siniflandirıld1. 1. grupta 44 hasta, 2. grupta 56 hasta mevcuttu. Hastaların demografik verileri geriye dönük olarak tarand1.

TZP (Trombositten Zengin Plazma) uygulaması, sadece tek hekim tarafından yapılmış olan ve sadece tek tip TZP kiti (GloPRP, GloTech Co.Ltd.KR) kullanılmış olan hastalar çalışmaya dâhil edildi. Hekimler arası uygulama farkı ve kitler arası etkinlik farkı oluşması bu şekilde engellenmiş oldu.

Radyolojik değerlendirme: Çalışmaya dahil edilen hastaların poliklinikte daha öneki başvurularında çekilmiş olan 2 yönlü diz grafileri ise başka bir araştırmacı tarafından değerlendirildi. $\mathrm{Bu}$ grafiler 
Kellgren-Lawrence diz osteoartrit radyolojik evrelemesine göre sınıflandırıldı (7) (Şekil 1).

\section{KELLGREN - LAWRENCE SINIFLAMASI}

EVRE I
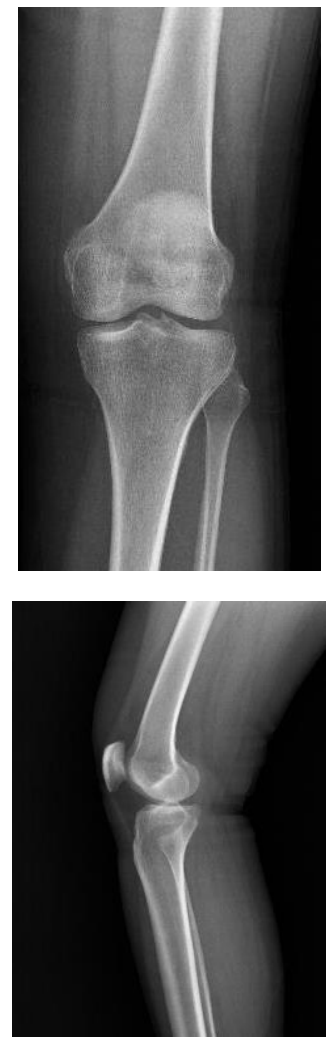

EVRE II
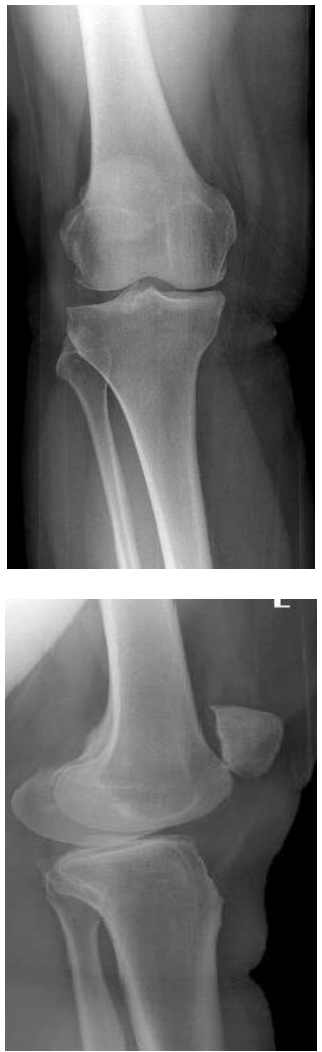

EVRE III
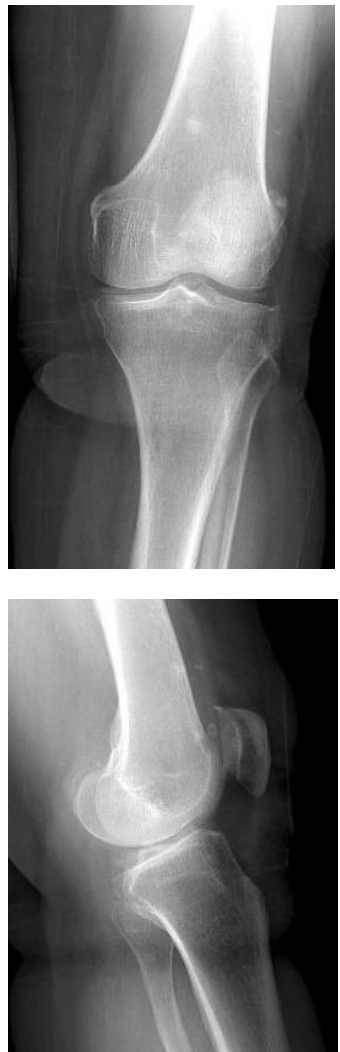

EVRE IV
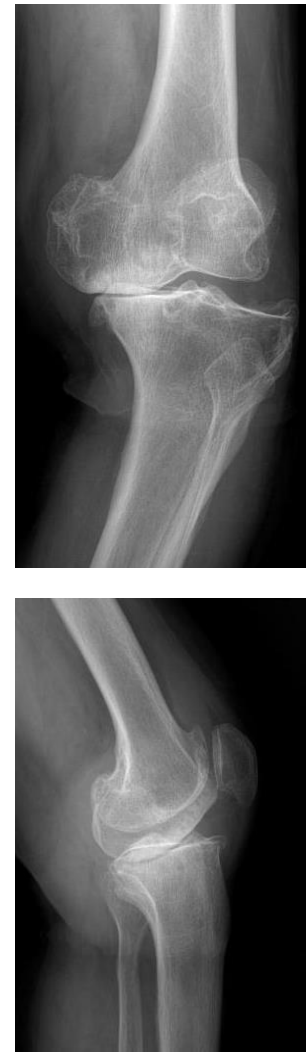

Şekil 1: Diz osteoartritinde Kellgren-Lawrence radyolojik evrelemesi

Bu sınıflandırmaya göre şüpheli, hafif, orta ve şiddetli olmak üzere 4 evre osteoartrit tipi tanımlanmıştır. Evre 1'de eklem aralığında şüpheli daralma ve muhtemel osteofit öncüsü lezyonlar mevcuttur. Evre 2'de belirgin osteofitler ve eklem aralığında şüpheli daralma mevcuttur. Evre 3'te orta derece osteofitlerin varlığına, belirgin eklem aralığında daralma ve kemik kontürlerinde şüpheli deformasyon eklenir. Evre 4'te ise geniş osteofitler, eklem aralığında belirgin daralma, ileri derecede skleroz ve kemik kontürlerinde belirgin deformite dikkati çekmektedir. Biz çalışmamızda Evre 1 ve 2 osteoartriti olan olguları birinci grupta ele alırken, Evre 3 ve 4 osteoartriti olan olguları ikinci gruba dahil ettik.

Ístatistiksel Değerlendirme
Lysholm Diz Fonksiyon Skorlama Sistemi

Lysholm diz skorlama sistemi diz fonksiyonelliğinin belirlenmesi için kullanılan bir ankettir. Hastalara aksama, destek kullanımı, kilitlenme, boşalma, merdiven çıkma, çömelme, şişlik ve ağrı ile ilgili sorular yöneltilir. Toplam 100 puan üzerinden değerlendirilir. Yüksek puan alınması iyi fonksiyonel durumu göstermektedir. (Şekil 2) Lysholm skorlama sisteminin Türkçe geçerlilik ve güvenirlik çalışması yapılmış ve rutin olarak kliniğimizde kullanılmaktadır (6). 
Tüm hastaların demografik özellikleri incelendi. Her iki gruptaki hastaların TZP yapılan dizlerinin enjeksiyon öncesi ve enjeksiyon sonrası Lysholm skorlarındaki değişim mix-model varyans analizi (ANOVA) testi ile istatistiksel olarak karşılaştırıldı. Örneklem miktarının küçük olması ve grupların homojen olmaması nedeni ile şüpheli ve hafif derecede osteoartrit bulguları olan hastalar ilk gruba alınd1. Orta ve ileri derece osteoartriti olan hastalar ise ikinci grup olarak planlandi. Non-parametrik verilerin karşılaştırılması gerçekleştirildi.

\section{BULGULAR}

Tablo 1: Verilerin demografik analizi ve sonuçların dağılımı.

\begin{tabular}{lcc}
\hline & Grup 1 & Grup 2 \\
\hline Osteoartrit evresi & Evre I ve II OA & Evre III ve IV OA \\
(Kellgren-Lawrence sınıflamasına göre) & 44 & 56 \\
Denek sayısı (n) & 52 & 64 \\
Yaş ortalaması & $3 / 1$ & $3 / 1$ \\
Cinsiyet (K/E) & 44 & 36 \\
Lysholm diz skoru (LDS) ortalaması & & 61 \\
(Enjeksiyon öncesi) & 85 & $25^{* *}$ \\
Lysholm diz skoru ortalaması & & $41^{*}$ \\
(Enjeksiyon sonrası) & & \\
LDS değişimi & & \\
\hline
\end{tabular}

(LDS: Lysholm diz skoru. $\left.{ }^{*} \mathrm{p}<0,05, * * \mathrm{p}>0,05\right)$

Ancak her iki gruptaki hastaların Lysholm skorlarının enjeksiyon sonrası arttığı belirlenmiştir. Her iki grubun TZP enjeksiyonu öncesindeki ve TZP enjeksiyonu sonrasındaki Lysholm skorları arasındaki
Ortopedi ve travmatoloji polikliniği kayıtlarında diz eklemine PRP yapılan 80 hastanın demografik özellikleri incelendiğinde hastaların yaş ortalamaları 1. grupta 52 ve 2 . Grupta 64 idi. Her iki grupta erkek ve kadın cinsiyetler arasında kadın (\%72) cinsiyet lehine bir dağılım mevcuttu. Hastaların şikâyetleri geriye dönük olarak incelendiğinde, tüm hastalarda istirahat eklem ağrısı, uzun süreli yürüyüş sonrası eklemde ağrı mevcuttu. Birinci gruptaki hastaların enjeksiyon öncesi ve sonrasındaki Lysholm diz skorları karşılaştırıldığında, istatistiksel olarak anlamlı bir fark bulunmuştur $(\mathrm{p}<0,05)$. Ancak 2. gruptaki Lysholm skorları arasında anlamlı bir fark elde edilememiştir ( $p>0,05)$ (Tablo 1). 


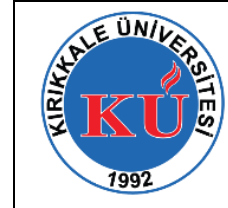

HASTANIN ADI SOYADI:

TELEFON:

\section{LYSHOLM SKORU}

TARAF/YAŞ:

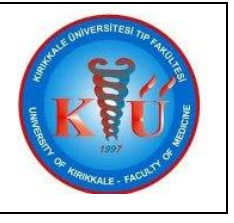

TARIH:

ÖNTANI:

\begin{tabular}{|l|l|l|}
\hline TOPALLAMA & a) Yok & 5 \\
\hline & b) Hafif ya da bazen & 3 \\
\hline & c) Ciddi (ağır) ve sürekli & 0 \\
\hline
\end{tabular}

\begin{tabular}{|l|l|l|}
\hline DESTEK & a) Yok & 5 \\
\hline & b) Baston veya koltuk değneği & 2 \\
\hline & c) Yük vermek imkansız (basamıyor) & 0 \\
\hline
\end{tabular}

\begin{tabular}{|l|l|c|}
\hline KİLITLENME & a) Yok & 15 \\
\hline & b) Takılma hissi var, kilitlenme yok & 10 \\
\hline & c) Ara sira (bazen) kilitlenme & 6 \\
\hline & d) Siklıkla kilitlenme & 2 \\
\hline & e) Muayenede kilitli diz & 0 \\
\hline
\end{tabular}

\begin{tabular}{|l|l|c|}
\hline GÜVENSIZLiK & a) Boşalma hissi yok & 25 \\
\hline & b) Spor veya ağır egzersizle bazen & 20 \\
\hline & c) Spor veya ă̆ır egzersizle sık sık (spor yapamıyor) & 15 \\
\hline & d) Günlük aktivitelerde bazen & 10 \\
\hline & e) Günlük aktivitelerde sık sık & 5 \\
\hline & f) Her adımda boşalma hissi & 0 \\
\hline
\end{tabular}

\begin{tabular}{|l|l|c|}
\hline AĞRI & a) Yok & 25 \\
\hline & b) Ağır egzersizde bazen ve hafif ağrı & 20 \\
\hline & c) Ağır egzersizde belirgin ağrı & 15 \\
\hline & d) 2 km.den fazla yürümekle veya sonrasında belirgin & 10 \\
\hline & e) 2 km.den az yürümekle veya sonrasında belirgin & 5 \\
\hline & f) Sürekli & 0 \\
\hline
\end{tabular}

\begin{tabular}{|l|l|c|}
\hline ŞişsiK & a) Yok & 10 \\
\hline & b) Ciddi egzersizle & 6 \\
\hline & c) Günlük aktivitelerle & 2 \\
\hline & d) Sürekli & 0 \\
\hline
\end{tabular}

\begin{tabular}{|l|l|c|}
\hline MERDIVEN ÇIKMA & a) Sorunsuz & 10 \\
\hline & b) Hafif zorlanma & 6 \\
\hline & c) Tek tek çıma & 2 \\
\hline & d) Çıkamıor & 0 \\
\hline
\end{tabular}

\begin{tabular}{|l|l|l|}
\hline ÇÖMELME & a) Sorunsuz & 5 \\
\hline & b) Hafif zorlanma & 4 \\
\hline & c) 90 dereceden fazla çömelememe & 2 \\
\hline & d) Çömelememe & 0 \\
\hline
\end{tabular}

Şekil 2: Lysholm diz fonksiyonelliği ölçeği 


\section{TARTIŞMA}

Diz osteoartritinin erken dönem cerrahi dışı tedavileri arasinda yer alan Trombositten Zengin Plazma uygulaması, son dönemde artan bir eğilimle rutin uygulamalar arasına girmiştir. Özellikle erken dönem osteoartriti bulunan hastalarda, TZP uyguladığımızda anlamlı sonuçlar elde ettik. Hastaların hem ağrısında azalma hem de fonksiyonelliğinde artma izlendi. Daha önce yapılan çalışmalarda da TZP tedavisinin diz osteoartritinde diğer tedavi modaliteleri kadar etkili olduğu gösterilmiştir. Di ve ark. TZP enjeksiyonunun en az intraartiküler hiyaluronik asit enjeksiyonu kadar etkin olduğunu göstermişlerdir (8). Yapılan başka bir prospektif çalışmada ise TZP tedavisinin proloterapiden ( $25 \%$ dekstroz) daha etkin olduğu bulunmuştur.(9) TZP yapılan hastalarda fonksiyonellikte artış ve ağrıda azalma görülmekte ise de Manyetik Rezonans Görüntüleme (MRG) ile incelendiğinde anlamlı bir fark oluşmamaktadır.(10) $\mathrm{Bu}$ çalş̧malarda osteoartrit evresi göz önüne alınmamış ve erken ya da geç dönem diz osteoartritleri arasında değerlendirme yapılmamıştır.

Diz osteoartritinde eklem içi TZP uygulamaları bir veya birden fazla uygulama şeklinde yapılabilir. Biz çalışmamızda tek enjeksiyon sonrası sonuçları değerlendirdik; Kallgren-Lawrence sınıflamasına göre evre I ve II olan hastaların tek enjeksiyondan daha fazla fayda gördüğünü ortaya koyduk. Yapılan bazı çalışmalarda tek doz TZP uygulamasının etkili olduğu gösterilmiştir $(3,10,11)$. Ancak Levy ve arkadaşları üçer hafta aralıklı 3 enjeksiyon önermektedirler (12). Özellikle Kellgren-Lawrence evre III ve IV olan hastalarda tek doz ile yeterli sonuç alınamayacağı da belirtilmektedir $(13,14)$.

Genel olarak TZP, içerdiği trombositlerin alfa granüllerinin degradasyonu ile açığa çıkan büyüme ve farklılaşma faktörleri aracılığıyla etki etmektedir (4). Erken evre diz osteoartriti olan hastalarımız ileri evre osteoartriti olanlara hastalara göre daha fazla fayda görmüştür. Bunda TZP'nın içerdiği büyüme ve farklılaşma faktörlerinin rol oynadığını düşünmekteyiz. $\mathrm{Bu}$ faktörler aracilığı ile doku yenilenmesinin belli bir dereceye kadar mümkün olacağ1 öngörülmektedir $\quad(2,3,12)$. Trombositlerin içerdiği başlıca büyüme faktörleri arasında PDGF (Trombosit kaynaklı büyüme faktörü), TGF (Transforme edici büyüme faktörü), FGF (Fibroblast büyüme faktörü), VEGF (vasküler endotel kaynaklı büyüme faktörü) ve çeşitli interlökinler (IL) yer alır (15-17). Eklem içi TZP enjeksiyonu sonrası açığa çıan bu faktörler endojen hyaluronik asit sentezini düzenleyerek kıkırdak dokunun yenilenmesinde ve korunmasinda rol alırlar. Ayrica eklemin lubrikasyonuna da katkıda bulunurlar $(18,19)$. Polikliniğimize başvuran hastalar arasında özellikle erken dönem osteoartriti olanların daha fazla fayda görmesini, eklem kıkırdak dokularının rejenerasyon kapasitesine bağlamaktayız. Benzer sonuçların alındığı bazı çalışmalarda da erken dönem osteoartritli dizlerde eklem içi TZP uygulamasının daha etkin olduğu gösterilmiştir $(13,14)$. Özellikle Kellgren Lawrence Tip I ve II hastalarda hem daha etkili hem de daha güvenli olduğunu gösteren çalışmalar yayınlanmıştır $(13,19)$.

Eklem içi TZP enjeksiyonu sonrası elde edilen kıkırdak rejenerasyonunda osteoartritin şiddeti kadar, hazırlanan plazmanın trombosit yoğunluğunun ve içerdiği lökosit miktarının da etkisi mevcuttur $(8,20,21)$. Genel olarak TZP preparatlarının kandaki trombosit konsantrasyonunun 3 ila 5 katına ulaşması beklenmektedir. Trombosit konsantrasyonunun 5 kattan daha fazla olmasının, etkinliği değiştirmediği gösterilmiş̧ir (21). Bizim çalışmamızda kullanılmış olan kitlerin trombosit konsantrasyonunu 5 katına kadar artırdığı bilinmektedir. Ancak kullanmış olduğumuz kitler lökositten ve trombositten zengin plazma hazırlamaktadır. Literatürde lökositten fakir TZP kullanılmasının daha etkili olduğuna dair çalışmalar mevcutsa da genel olarak literatür, 
trombositlerin ayrışması esnasında lökositlerin ayrıştırılmasının zor ve gereksiz olduğu konusunda hemfikirdir (5,13,22-24). Mevcut lökositlerin enflamasyonu baskılamasının, eklem ağrısının azalmasında rol oynadığı düşünülmektedir (11). Bizim çalışmamızda da lökositlerin ayrıştırılmaması herhangi bir probleme neden olmamış, TZP etkinliğine de katkıda bulunmuştur.

Çalışmamızın retrospektif tasarımda yapılmış olması en önemli eksikliğidir. Hastaların verilerine geriye dönük olarak ulaşılmıştır. $\mathrm{Bu}$ yüzden erken dönem fonksiyonları ve ağrıya yanıtları tam olarak değerlendirilememiştir. Çalışmamızın bir diğer eksik tarafı, TZP dışında başka bir tedavi modalitesi veya plasebo ilaç uygulaması ile karşılaştırma olanağı bulamamış olmamızdır. İleride yapılacak daha geniş çaplı kontrollü prospektif çalışmalar ile daha değerli bulgulara ulaşılacaktır. TZP'nın etkinliğinin daha açık bir şekilde ortaya konması mümkün olacaktır.

Etik Kurul Onamı: Kırıkkale Üniversitesi Girişimsel Olmayan Çalışmalar Etik Kurul Başkanlığı; 18.12.2019-2019.11.08.

\section{KAYNAKLAR}

1. Price AJ, Alvand A, Troelsen A, Katz JN, Hooper G, Gray A et al. Knee replacement. Lancet. 2018;392(10158):1672-82.

2. Dhillon MS, Patel S, John R. PRP in OA knee update, current confusions and future options. SICOT J. 2017;3:27.

3. Patel S, Dhillon MS, Aggarwal S, Marwaha N, Jain A. Treatment with platelet-rich plasma is more effective than placebo for knee osteoarthritis: a prospective, double-blind, randomized trial. Am J Sports Med. 2013;41(2):356-64.

4. Gobbi A, Fishman M. Platelet-rich plasma and bone marrow-derived mesenchymal stem cells in sports medicine. Sports Med Arthrosc Rev. 2016;24(2):69-73.

5. Braun HJ, Kim HJ, Chu CR, Dragoo JL. The effect of platelet-rich plasma formulations and blood products on human synoviocytes: implications for intra-articular injury and therapy. Am J Sports Med. 2014;42(5):1204-10.

6. Celik D, Coskunsu D, Kilicoglu O. Translation and cultural adaptation of the Turkish Lysholm knee scale: ease of use, validity, and reliability. Clin Orthop Relat Res. 2013;471(8):2602-10.

7. Kellgren JH, Lawrence JS. Radiological assessment of osteo-arthrosis. Ann Rheum Dis. 1957;16(4):494-502.

8. Di Y, Han C, Zhao L, Ren Y. Is local plateletrich plasma injection clinically superior to hyaluronic acid for treatment of knee osteoarthritis? A systematic review of randomized controlled trials. Arthritis Res Ther. 2018;20(1):128.

9. Rahimzadeh P, Imani F, Faiz SHR, Entezary SR, Zamanabadi MN, Alebouyeh MR. The effects of injecting intra-articular platelet-rich plasma or prolotherapy on pain score and function in knee osteoarthritis. Clin Interv Aging. 2018;13:73-9.

10. Guillibert C, Charpin C, Raffray M, Benmenni A, Dehaut FX, El Ghobeira G et al. Single injection of high volume of autologous pure prp provides a significant improvement in knee osteoarthritis: A prospective routine care study. Int J Mol Sci. 2019;20(6).

11. Martini LI, Via AG, Fossati C, Randelli F, Randelli P, Cucchi D. Single Platelet-Rich Plasma Injection for Early Stage of Osteoarthritis of the Knee. Joints. 2017;5(1):2-6.

12. Levy DM, Petersen KA, Scalley Vaught M, Christian DR, Cole BJ. Injections for knee osteoarthritis: corticosteroids, viscosupplementation, platelet-rich plasma and 
autologous stem cells. Arthroscopy. 2018;34(5):1730-43.

13. Sucuoglu H, Ustunsoy S. The short-term effect of PRP on chronic pain in knee osteoarthritis. Agri. 2019;31(2):63-9.

14. Huang Y, Liu X, Xu X, Liu J. Intra-articular injections of platelet-rich plasma, hyaluronic acid or corticosteroids for knee osteoarthritis: A prospective randomized controlled study. Orthopade. 2019;48(3):239-47.

15. Bansal H, Comella K, Leon J, Verma P, Agrawal $\mathrm{D}$, Koka $\mathrm{P}$ et al. Intra-articular injection in the knee of adipose derived stromal cells (stromal vascular fraction) and platelet rich plasma for osteoarthritis. J Transl Med. 2017;15(1):141.

16. Frechette JP, Martineau I, Gagnon G. Plateletrich plasmas: growth factor content and roles in wound healing. J Dent Res. 2005;84(5):434-9.

17. Xing D, Wang B, Zhang W, Yang Z, Hou Y, Chen $\mathrm{Y}$ et al. Intra-articular platelet-rich plasma injections for knee osteoarthritis: An overview of systematic reviews and risk of bias considerations. Int $\mathrm{J}$ Rheum Dis. 2017;20(11):1612-30.

18. Noth U, Steinert AF, Tuan RS. Technology insight: adult mesenchymal stem cells for osteoarthritis therapy. Nat Clin Pract Rheumatol. 2008;4(7):371-80.

19. Southworth TM, Naveen NB, Tauro TM, Leong NL, Cole BJ. The Use of Platelet-Rich Plasma in Symptomatic Knee Osteoarthritis. J Knee Surg. 2019;32(1):37-45.

20. Fotouhi A, Maleki A, Dolati S, Aghebati-Maleki A, Aghebati-Maleki L. Platelet rich plasma, stromal vascular fraction and autologous conditioned serum in treatment of knee osteoarthritis. Biomed Pharmacother. 2018;104:652-60.
21. Foster TE, Puskas BL, Mandelbaum BR, Gerhardt MB, Rodeo SA. Platelet-rich plasma: from basic science to clinical applications. Am J Sports Med. 2009;37(11):2259-72.

22. Kesikburun S, Tan AK, Yilmaz B, Yasar E, Yazicioglu K. Platelet-rich plasma injections in the treatment of chronic rotator cuff tendinopathy: a randomized controlled trial with 1-year follow-up. Am J Sports Med. 2013;41(11):2609-16.

23. Riboh JC, Saltzman BM, Yanke AB, Fortier L, Cole BJ. Effect of Leukocyte Concentration on the Efficacy of Platelet-Rich Plasma in the Treatment of Knee Osteoarthritis. Am J Sports Med. 2016;44(3):792-800.

24. Kanwat H, Singh DM, Kumar CD, Alka B, Biman S, Aman H. The effect of intra-articular allogenic platelet rich plasma in Dunkin-Hartley guinea pig model of knee osteoarthritis. Muscles Ligaments Tendons J. 2017;7(3):426-34. 